\title{
Improved management and 10-year outcomes in diabetic kidney disease in routine clinical care
}

\author{
SARAH O'BRIEN, KEVIN HARDY
}

\begin{abstract}
Aim: To examine the impact of service re-design on management and 10-year outcomes in diabetic kidney disease in a real world setting.

Methods: We established a highly structured, nurse-led diabetic kidney clinic to deliver consistent evidence-based care processes (blood pressure control (BP), glycaemic control $\left(\mathrm{HbA}_{1 \mathrm{c}}\right)$, renin-angiotensin-aldosterone (RAAS) blockade, lipid-lowering therapy and smoking cessation) and assessed impact on death, doubling of serum creatinine, new end-stage renal disease (ESRD), new cardiovascular (CV) events and decline in estimated glomerular filtration rate (eGFR).

Results: There were $\mathbf{2 6 1}$ patients in the 10-year cohort: 9 casenotes were missing and 23 had been destroyed. Our analysis is based on 229 patients for whom we had data (1,799 patient-years of follow-up): 28 (12\%) had new CV events, $22(10 \%)$ progressed to ESRD (16 dialysis, 3 conservative treatment, 3 transplant) and $87 / 229$ (38\%) died. At last assessment, mean BP was $129 / 70 \mathrm{mmHg}, \mathrm{HbA}_{1 \mathrm{c}} 59$ $\mathrm{mmol} / \mathrm{mol}(7.6 \%)$ and LDL-cholesterol $1.81 \mathrm{mmol} / \mathrm{L}$. Mean rate of eGFR decline was $0.15 \mathrm{~mL} / \mathrm{min} / \mathrm{month}$. Expressed per 100-patient-years, mortality $4.83, \mathrm{CV}$ events 1.56 , doubling serum creatinine 1.72, and ESRD 1.22 compare favourably with landmark trials.

Conclusions: A highly structured, nurse-led, diabetic kidney clinic can translate consistent evidence-based care processes into favourable 10-year outcomes in routine clinical care.

Br J Diabetes Vasc Dis 2015;15:27-30
\end{abstract}

Key words: diabetes mellitus, diabetic kidney disease, nephropathy, death, dialysis, doubling of serum creatinine

\section{Introduction}

DKD is the leading cause of end-stage renal failure worldwide, affecting $15-25 \%$ of people with type 1 diabetes and up to

St Helens Diabetes Centre, Merseyside, UK.

Address for correspondence: Professor Kevin Hardy Diabetes Centre, St Helens Hospital, Marshalls Cross Road, St Helens, Merseyside, WA9 3DA, UK

Tel: +44 (0)1744 646497 Fax: +44 (0)1744 646491

E-mail: kevin.hardy@sthk.nhs.uk

http://dx.doi.org/10.15277/bjdvd.2015.002

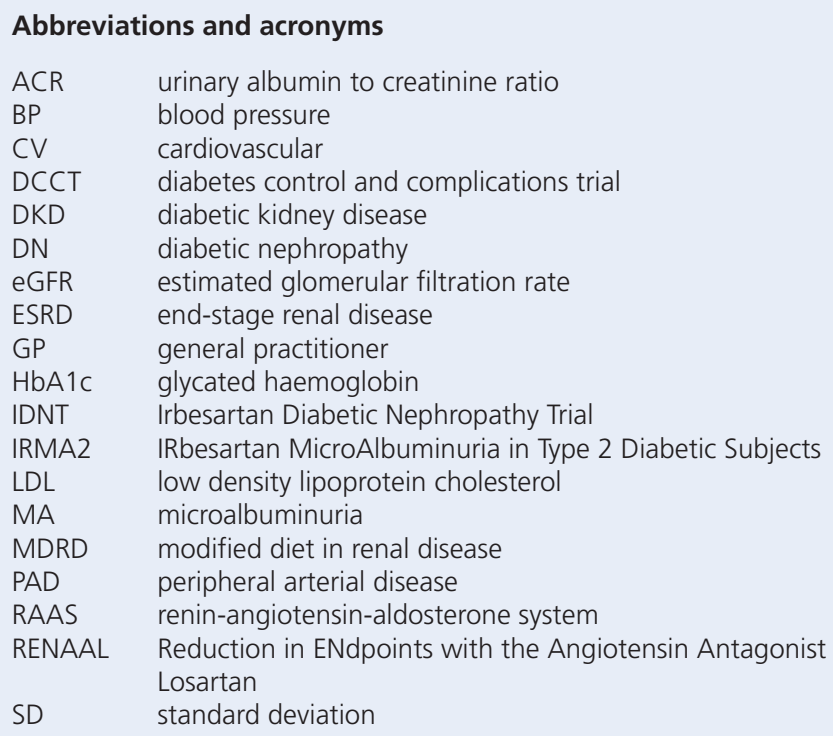

$25 \%$ of those with type 2 diabetes. ${ }^{1}$ In one 12 -year study of 4,714 patients, ${ }^{2}$ DKD was associated with a $5-8$ fold increase in mortality compared to people with diabetes but no proteinuria.

Intensive blood glucose control ${ }^{3-5}$ and blood pressure control6,7 retard the development and progression of DKD in both type 1 and type 2 diabetes. The Steno 2 study demonstrated that after just 3.8 years, intensive multifactorial $\mathrm{CV}$ risk factor management in people with type 2 diabetes and microalbuminuria reduced progression of $D K D$, retinopathy and autonomic neuropathy. ${ }^{8}$

Three large clinical trials (IRMA2, ${ }^{9}$ IDNT, ${ }^{10}$ RENAAL ${ }^{11}$ ) have demonstrated that RAAS blockade in type 2 diabetes with DKD improves not only surrogate outcomes, but also doubling of serum creatinine, development of ESRD and mortality. ${ }^{9-11}$

The challenge for many clinicians is transferring findings from these large trials into routine clinical care. Indeed, it has been suggested that deficiencies in clinical management of those with or at high risk of DKD contribute to its poor outcome. ${ }^{12}$

The aim of this study was to establish whether successful outcomes of major clinical trials in DKD could be reproduced in a routine care setting.

\section{Patients and methods}

Service re-design

Thirteen years ago, in our service, local management of diabetic kidney disease was poor, unstructured and inconsistent. Hospital 
outpatients were largely seen in 'general diabetes clinics' by a range of clinicians and a minority attended specialist nephrologist clinics at the tertiary centre; there was poor triage to the right setting and no shared care.

We established a physician-led, nurse-run secondary care Diabetic Kidney Clinic to focus multifactorial interventions from international guidelines to reduce DKD progression and adverse outcomes. ${ }^{13-15}$ We agreed with local nephrologists a system of shared care for advanced renal patients (including those on renal replacement therapy) and we discharged stable, lower risk (typically stable plus eGFR $>45$ and ACR $<45$ ) patients to primary care.

DKD patients were filtered into a specific 'new patient clinic' for consultant assessment, and then followed up in one of 2-3 (currently two) dedicated nurse-run DKD clinics, where approximately eight patients are seen at 30-minute intervals. After each 4-hour clinic, the consultant and nurse discuss all patients (1 hour); consistency has been maintained by using the same consultant and nurse (excluding maternity leave). Criteria for the kidney clinic were albuminuria with or without reduced eGFR.

BP control, RAAS blockade and lipid control were managed aggressively according to pre-defined algorithms until targets were achieved. Patients received lifestyle advice from a dietitian including weight management, exercise, alcohol and salt restriction and this was reinforced at each clinic visit by the nurse. If LDL-cholesterol was above target, medication was initiated, typically a statin at maximum dose and, at 10 years, 206 patients $(90 \%)$ were treated with cholesterol lowering agents.

RAAS blockade was used as first-line therapy for BP control and additional agents added as necessary. At 10 years, 209 (91\%) of patients were on maximum dose ACE-inhibitor or Angiotensin II receptor blocker. The median number of BP drugs (including RAAS blockade) was 3, typically at the maximum dose.

\section{Process measures and surrogate outcomes}

We recorded systolic and diastolic BP (seated, after 5 minutes rest), LDL-cholesterol, and patients receiving maximum single-agent RAAS blockade and self-reported current smokers (smoking within 3 months of index date). We measured $\mathrm{HbA}_{1 \mathrm{c}}$ (DCCT aligned assay, reference range $27-44 \mathrm{mmol} / \mathrm{mol}$ [4.6-6.2\%]), serum creatinine, eGFR (MDRD $\left.{ }^{16}\right)$ and patient's proteinuria status (nephropathy [DN], microalbuminuria [MA] or normal) and change of status. MA was defined as ACR $>2.5 \mathrm{mg} / \mathrm{mmol}$ (men) or $>3.5$ $\mathrm{mg} / \mathrm{mmol}$ (women) and $<30 \mathrm{mg} / \mathrm{mmol}$ on two separate occasions and $\mathrm{DN}$ as $\mathrm{ACR}>30 \mathrm{mg} / \mathrm{mmol}$ on two separate occasions. The laboratory reported ACR values up to $300 \mathrm{mg} / \mathrm{mmol}$ and values thereafter as $>300$ (with a $\mathrm{mg} / \mathrm{dL}$ urine protein concentration in the early years and subsequently protein to creatinine ratio), so although we can report with confidence transitions between normal, MA and DN and we can report the percentage who experienced a rise or fall in proteinuria, we cannot report mean levels of proteinuria or mean change in proteinuria.

\section{Hard outcomes}

Mortality data were obtained from the hospital patient administration system and GP data and dialysis rates from patients themselves, cross-referenced with information from the local nephrologists and the dialysis unit; incidence of CV events (heart attack or acute coronary syndrome, newly diagnosed angina, stroke or transient ischaemic attack or new PAD) were patient-reported (PAD supported by foot examination).

\section{Statistical analysis}

Normally distributed data are expressed as mean (SD) and nonnormal data as median (range). Within patient comparisons from baseline to last result were compared using two-tailed, paired t-tests. Hard outcome data are reported as rates per 100-patientyears for comparison with landmark trials. Significance was set at $p<0.05$ and no correction was made for multiple comparisons. Analyses were carried out using Microsoft Excel 2003, SP3.

\section{Results}

\section{Demographics}

There were 261 patients in the 10-year cohort: nine sets of notes were missing and 23 sets had been destroyed (all of these patients had died). Our analysis is based on 229 patients for whom data were available (1,799 patient-years of follow-up). Mean (SD) age was 67 (11) years and diabetes duration was 20 (10) years; 162 (71\%) were male, $39(17 \%)$ had type 1 diabetes, $190(83 \%)$ had type 2 diabetes; $143(62 \%)$ had nephropathy, $86(38 \%)$ had microalbuminuria, $216(94 \%)$ had reduced eGFR and $142(62 \%)$ had CV disease at baseline.

Table 1 shows selected characteristics in our cohort compared with similar characteristics in relevant landmark clinical trials.

Table 1 Characteristics of 229 diabetic kidney disease patients together with similar data from relevant landmark trials

\begin{tabular}{|c|c|c|c|c|}
\hline & $\begin{array}{l}\text { St Helens } \\
\text { Clinic }\end{array}$ & $\begin{array}{l}\text { IRMA2 } \\
\text { 300mg } \\
\text { Group }\end{array}$ & $\begin{array}{l}\text { RENAAL } \\
\text { Losartan } \\
\text { Group }\end{array}$ & $\begin{array}{l}\text { IDNT } \\
\text { Irbesartan } \\
\text { Group }\end{array}$ \\
\hline Number subjects & 229 & 194 & 751 & 579 \\
\hline Age (years) & 67 & 57 & 60 & 59 \\
\hline Male (\%) & 71 & 71 & 62 & 65 \\
\hline $\begin{array}{l}\text { Duration } \\
\text { diabetes (years) }\end{array}$ & 20 & 9.2 & Not given & 15 \\
\hline $\begin{array}{l}\text { CV disease } \\
\text { at baseline (\%) }\end{array}$ & 60 & 26 & 27 & 27 \\
\hline Smoking (\%) & 9 & 17 & 20 & - \\
\hline $\begin{array}{l}\mathrm{HbA}_{1 \mathrm{c}}(\%) \\
\text { (latest for St H) }\end{array}$ & 7.6 & 7.1 & 8.5 & 8.1 \\
\hline $\begin{array}{l}\text { Systolic BP (mmHg) } \\
\text { (latest) }\end{array}$ & 129 & 141 & 140 & 140 \\
\hline $\begin{array}{l}\text { Diastolic BP (mmHg) } \\
\text { (latest) }\end{array}$ & 70 & 83 & 74 & 77 \\
\hline $\begin{array}{l}\text { Baseline serum } \\
\text { creatinine }(\mu \mathrm{mol} / \mathrm{l})\end{array}$ & 127 & $\begin{array}{l}\text { M: } 97 \\
F: 88\end{array}$ & 168 & 148 \\
\hline $\begin{array}{l}\text { LDL-cholesterol } \\
(\mathrm{mmol} / \mathrm{l})\end{array}$ & 1.95 & 3.48 & 3.7 & - \\
\hline
\end{tabular}


Table 2 Characteristics of patients who survived compared with those that died

\begin{tabular}{lll}
\hline & Survivors $(\mathbf{n}=\mathbf{1 4 2})$ & Dead $(\mathbf{n}=\mathbf{8 7})$ \\
Age (years) & 65 & 71 \\
Diabetes duration (years) & 20 & 19 \\
Nephropathy $(\mathrm{ACR}>30)$ at baseline & $56 \%$ & $74 \%$ \\
Dialysis & $6 \%$ & $8 \%$ \\
Conservative Mx of ESRD & 2 & 1 \\
Smoking & $8 \%$ & $9 \%$ \\
CV disease & $56 \%$ & $71 \%$ \\
Last systolic BP & 128 & 131 \\
Last diastolic BP & 70 & 69 \\
Last HbA 1 ( $\mathrm{mmol} / \mathrm{mol})$ & 61 & 56 \\
Baseline creatinine $(\mu \mathrm{mol} / \mathrm{l})$ & 125 & 133 \\
Last creatinine $(\mu \mathrm{mol} / \mathrm{l})$ & 154 & 235 \\
Last LDL-cholesterol $(\mathrm{mmol} / \mathrm{l})$ & 1.69 & 2.07
\end{tabular}

\section{Surrogate measures}

At the last assessment, 209 (91\%) patients were on maximum dose, single-agent RAAS blockade and it was contraindicated (recurrent hyperkalaemia) in $20(9 \%)$. Twenty patients (10\%) admitted to smoking. Mean (SD) BP was $129(17) / 70 \mathrm{mmHg}, \mathrm{HbA}_{1 \mathrm{c}}$ 59 (8) $\mathrm{mmol} / \mathrm{mol}(7.6(1.4) \%)$ and LDL-cholesterol $1.81(0.8)$ $\mathrm{mmol} / \mathrm{L}$.

Of the 229 patients, 135 (59\%) had BP <130/80; 169 (74\%) had LDL-cholesterol $<2.0 \mathrm{mmol} / \mathrm{L}$ and $165(72 \%)$ had $\mathrm{HbA}_{1 \mathrm{c}}$ $<58 \mathrm{mmol} / \mathrm{mol}(7.5 \%)$.

Mean rate of eGFR decline was $0.15(0.35) \mathrm{mL} / \mathrm{min} / \mathrm{month}$. Twelve percent (10/86) of MA patients progressed to DN and $24 \%$ (20/86) of MA patients returned to normal ACR; 29/143 (20\%) patients with DN regressed to MA and 7/143 (5\%) DN patients returned to normal ACR.

\section{Outcome measures}

Twenty-eight (12\%) patients had new CV events, 22 progressed to ESRD ( 16 dialysis, 3 transplant and 3 conservative treatment) and $87(38 \%)$ died. Expressed per 100-patient-years, mortality was $4.8, C V$ events 1.56 , doubling serum creatinine 1.72 , and renal replacement 1.05 .

Table 2 compares survivors with those that died. Survivors were younger and with better BP control, lower LDL-cholesterol, lower creatinine and less baseline $\mathrm{CV}$ disease.

\section{Discussion}

Diabetes is reaching epidemic proportions across much of the globe and the downstream impact of diabetic kidney disease will overwhelm renal replacement services and health services unless action is taken to prevent development and progression of DKD. There is robust evidence from well designed clinical trials to guide prevention and management of DKD, but translating this evidence into day-to-day real world practice is a major challenge.
Table 3 Doubling of serum creatinine, progression to ESRD and Death in DKD with same measures in landmark trials (events expressed per 100-patient-years) for comparison

\begin{tabular}{|c|c|c|c|}
\hline & St Helens & RENAAL $^{10}$ & IDNT $^{9}$ \\
\hline & $\begin{array}{l}\text { DKD } \\
\text { Clinic }\end{array}$ & $\begin{array}{l}\text { Losartan } \\
\text { Group }\end{array}$ & $\begin{array}{l}\text { Irbesartan } \\
\text { Group }\end{array}$ \\
\hline Doubling of serum creatinine & 1.72 & 7.9 & 3.9 \\
\hline ESRD * & 1.22 & 6.8 & 5.4 \\
\hline Total mortality & 4.8 & 6.8 & 5.8 \\
\hline
\end{tabular}

*Note: ESRD was defined as patients requiring renal replacement therapy in our study, in RENAAL it was also defined as the need for long term dialysis or transplant and in IDNT it was defined as initiation of dialysis, transplant or serum creatinine of $530 \mu \mathrm{mol} / \mathrm{l}$ or more.

Our Diabetes Unit is of average size and staffing levels in a medium-sized acute hospital serving a largely deprived $(350,000)$ population in northwest England (Index of Multiple Deprivation: $5^{\text {th }}, 27^{\text {th }}$ and $51^{\text {st }}$ of 326 most deprived areas in England) and, prior to this initiative, diabetic kidney care was poor. The aim of our service redesign was to improve local patient care, but better care and better outcomes should be transferable to elsewhere in the NHS and beyond.

Most patients achieved and sustained target blood pressure, $\mathrm{HbA}_{1 \mathrm{c}}$ and LDL-cholesterol, RAAS blockade and smoking cessation, but in addition decline in renal function was largely attenuated (mean fall in eGFR $0.15 \mathrm{~mL} / \mathrm{min} /$ month; American Diabetes Association target $<0.17$ ); incident $C V$ disease was modest ( $12 \%$ of patients in 10 years) ${ }^{17}$ and ESRD (1.05) and mortality (4.8) rates (per 100 patient-years) compared favourably with international trials.

This was not a rigorously controlled randomised trial but it was an attempt to translate randomised controlled trial evidence into real-world care. All data from 32 patients were missing and they all died, so our estimate of mortality, and by inference other hard outcome measures, is an underestimate. However, even if we add all of these deaths and assume all of these patients experienced a doubling of serum creatinine, the mortality rate (6.6) and rate of doubling of serum creatinine (3.5) per 100 patient-years still benchmarks favourably with international trials (Table 3 ).

Inevitably, using external benchmarks rather than randomised controls introduces potential bias. Our patients were similar to those of RENAAL, IRMA2 and IDNT, but differed in important respects (Table 1): patients at St Helens were older and of longer diabetes duration and had a higher prevalence of CV disease (all favouring a worse outcome), but we had fewer smokers and we achieved significantly better blood pressure and lipid control.

Another limitation of our study is that we were unable to report accurate figures for proteinuria. Our laboratory reports a ceiling ACR of $>300 \mathrm{mg} / \mathrm{mmol}$ and the method used to measure proteinuria in the clinic has varied over the course of the study. As was the case with many units, we moved from older measures of protein excretion (24 hour urinary protein and timed albumin excretion rate collections) to ACRs because of the inac- 


\section{Key messages}

- Improved clinical outcomes, including hard endpoints, comparable to those from major randomised studies of DKD conducted in centres of clinical excellence, are transferable to routine clinical care

- The development of an evidence-based target-driven secondary care specialist clinic focusing on high risk patients facilitates improved outcomes

curacy of timed collections. Although we cannot therefore report proteinuria rates, we can nevertheless describe with confidence transitions from DN, MA and normal protein excretion.

The strength of our study is that it not only assesses process change and alterations in surrogate endpoints, but also describes changes in hard outcomes over a sustained 10-year period. By virtue of the care pathway that informs and drives our clinic care, we are able to describe, in great detail, exactly how care was restructured and delivered. The resource implications of our re-design were minimal: some 4-6 hours of consultant time and 8-12 hours of nurse time per week (all of which was re-deployment of existing resources), together with some very modest paper costs for the pathway. We perform more blood and urine tests than a decade ago, but nothing above that recommended by national guidance for DKD patients. It is beyond the scope of this work to undertake a health economic assessment.

In summary, service re-design with minimal additional resources has transformed our secondary care service for people with DKD to one that delivers effective care and favourable 10-year outcomes.

\section{Conflict of interest None}

Funding This work was supported by an unrestricted educational grant to Professor Hardy from Pfizer.

Acknowledgements The authors would like to acknowledge the work in the clinic by Jan Cardwell during Prof. O'Brien's absence on maternity leave. Data were presented as an abstract at Diabetes UK Annual Scientific Session, 2012: Abstract reference: O'Brien SV, Nair S, Hardy KJ. Intensive diabetic nephropathy management is associated with sustained clinical improvements and favourable outcomes over ten years. Diabetic Med 2012;27(suppl1): A78 \& P390.

\section{References}

1. Hovind $P$, Tarnow $L$, Rossing $P$, et al. Predictors for the development of microalbuminuria and macroalbuminuria in patients with type 1 diabetes: inception cohort study. BMJ 2004;328:1105. http://dx.doi.org/10.1136/bmj.38070.450891.FE
2. Wang SL, Head J, Stevens L, Fuller JH. Excess mortality and its relation to hypertension and proteinuria in diabetic patients. The World Health Organisation Multinational Study of Vascular Disease in Diabetes. Diabetes Care 1996;19:305-12. http://dx. doi.org/10.2337/diacare.19.4.305

3. Diabetes Control and Complications Trial Research Group. The effect of the intensive treatment of diabetes on the development and progression of long-term complications in insulin-dependent diabetes mellitus. $N$ Engl J Med 1993;329:977-86.

http://dx.doi.org/10.1056/NEJM199309303291401

4. UKPDS Study Group. Intensive blood glucose control with sulphonylureas of insulin compared with conventional treatment and risk of complications in patients with type 2 diabetes mellitus. Lancet 1998;352:837-853.

5. OhkuboY, Kishikawa H, Araki E, et al. Intensive insulin therapy prevents the progression of diabetic microvascular complications in Japanese patients with non-insulin-dependent diabetes mellitus: a randomized prospective 6-year study. Diabetes Res Clin Pract 1995;28:103-17. http://dx.doi.org/10.1016/0168-8227(95)01064-K

6. UKPDS Study Group. Tight blood pressure control and risk of macrovascular and microvascular complications in type 2 diabetes: UKPDS 38. BMJ 1998;317:703-13. http://dx.doi.org/10.1136/bmj.317.7160.703

7. Lewis EJ, Hunsicker LG, Bain RP, Rohde RD, for the Collaborative Study Group. The effect of angiotensin-converting-enzyme inhibition on diabetic nephropathy. N Engl J Med 1993;329:1456-62. http://dx.doi.org/10.1056/NEJM199311113292004

8. Gaede $P$, Vedel $P$, Parving $H$, Pederson $O$. Intensified multifactorial intervention in patients with type 2 diabetes and microalbuminuria: the Steno type 2 randomised study. Lancet 1999;353:617-22. http://dx.doi.org/10.1016/S0140-6736(98)07368-1

9. Parving $\mathrm{HH}$, Lehnert $\mathrm{H}$, Brochner-Mortenson $\mathrm{B}$, et al. The effect of irbesartan on the development of diabetic nephropathy in patients with type 2 diabetes. N Engl J Med 2001;345:870-8. http://dx.doi.org/10.1056/NEJMoa011489

10. Lewis EJ, Hunsicker, LG, Clarke WR, et al. Renoprotective effect of the antagiotensin-receptor antagonist irbesartan in patients with nephropathy due to type 2 diabetes. N Engl J Med 2001;345:851-60. http://dx.doi.org/10.1056/NEJMoa011303

11. Brenner BM, Cooper ME, Zeeuw D, Keane WF. Effects of losartan on renal and cardiovascular outcomes in patients with type 2 diabetes and nephropathy. N Engl J Med 2001;345:861-9. http://dx.doi.org/10.1056/NEJMoa011161

12. Mogensen CE, Cooper ME. Diabetic renal disease: from recent studies to improved clinical practice. Diabet Med 2004;21:4-17. http://dx.doi.org/10.1111/j.1464-5491.2004.01121.x

13. ADA (American Diabetes Association). Nephropathy in Diabetes (Position Statement). Diabetes Care 2004;27(Suppl.1):S79-S83. http://dx.doi.org/10.2337/diacare.27.2007.S79

14. National Institute for Clinical Excellence. Management of type 2 diabetes. Renal disease - prevention and early management. Inherited Clinical Guideline F. London, NICE, 2005.

15. Renal Association. Treatment of adults and children with renal failure: standards and audit measures, 3rd Edition, 2002. www.renal.org/Standards/RenalStandards_2002b.pdf

16. Rigalleau MD, Lasseur C, Perlemoine C, et al. Estimation of glomerular filtration rate in diabetic subjects. Cockcroft Gault or Modification of Diet in Renal Disease study Equation? Diabetes Care 2005;28:838-43. http://dx.doi.org/10.2337/diacare.28.4.838

17. HOPE (Heart Outcomes Prevention Evaluation) Study Investigators. MICRO_HOPE Substudy. Effects of Ramipril on cardiovascular and microvascular outcomes in people with diabetes mellitus. Lancet 2000; 355:253-59. http://dx. doi.org/10.1016/\$0140-6736(99)12323-7 